\title{
Dynamic and Postdeformation Recrystallization of Nuclear-Grade 316LN Stainless Steel
}

\author{
R. H. Zhang, ${ }^{\text {a,b }}$ Z. H. Wang, ${ }^{\text {a,c }}$ Z. P. Shi, ${ }^{c}$ B. Wang, ${ }^{\text {a }}$ and W. T. Fu ${ }^{a, 1}$
}

a State Key Laboratory of Metastable Materials Science and Technology, Yanshan University, Qinhuangdao, China

${ }^{\mathrm{b}}$ Hebei Province Key Laboratory of Modern Metallurgy, College of Metallurgy and Energy, Hebei United University, Tangshan, China

${ }^{c}$ Key Laboratory of Advanced Forging \& Stamping Technology and Science, Ministry of Education of China, College of Mechanical Engineering Yanshan University, Qinhuangdao, China

${ }^{1}$ wtfu@ysu.edu.cn; zrh1980@126.com

Nuclear-grade 316LN stainless steel was subjected to single and double compressions at 1173-1473 K and strain rates of $0.01-10 \mathrm{~s}^{-1}$. The dynamic and postdeformation recrystallization was investigated through analysis of the stress-strain curves and microstructure evolution. The thermal deformation equation and the quantitative relationships between the critical stress for the initiation of dynamic recrystallization and the Zener-Hollomon parameter, $Z$, and between the dynamic recrystallization grain size $D$ and $Z$ were derived. Dynamic recrystallization developed through an ordinary mechanism at low $Z$ values and through a necklace mechanism at high $Z$ values, with a critical $Z$ value of about $3.6 \cdot 10^{16}$. At 1273-1473 K, softening of 316LN stainless steel after deformation was characterized by an Avrami-type equation, where the Avrami parameter, $n$, has no appreciable temperature dependence, and an average value of $n$ and the activation energy, $Q_{\text {rex }}$, were 0.68 and $129 \mathrm{~kJ} / \mathrm{mol}$, respectively.

Keywords: 316LN stainless steel, hot deformation, dynamic recrystallization (DRX), postdeformation recrystallization.

Introduction. Type 316 stainless steels are widely used in food, chemical, and energy industries owing to their good physical, chemical, and mechanical properties. Since steels of this grade arevery sensitive to intergranular stress corrosion, their carbon content needs to be slightly reduced. To compensate for the associated loss in strength, nitrogen is added to the steel, producing 316LN stainless steel with excellent pitting and stress corrosion resistance, good creep resistance, and high-temperature mechanical properties. This steel is widely applied in many industrial components, such as vessels, pipes, grid plates, support structures, etc. These components are mainly manufactured using hot-rolling and hotforging processes. Through thermal deformation, not only the required shape but also the desired fine structure can be obtained.

However, 316LN stainless steel essentially belongs to the class of coarse-grained steels. Coarse and mixed grained structures, which cannot be eliminated by thermal treatment, are usually formed in the hot-working process. Therefore, being able to exert microstructure control in the hot-working regime is very important for manufacturing 316LN stainless steel products. With respect to microstructure control, the dynamic evolution of the microstructure [1,2] and the static recrystallization behavior [3] have been investigated, and a recrystallization model has been developed [4], which was successfully applied to hot bar rolling. 316LN stainless steel contains relatively less carbon and more nitrogen than the 316 type, which leads to significant differences in the recrystallization behavior of these two steel types Although the flow behavior of $316 \mathrm{LN}$ stainless steel has previously been investigated, the recrystallization behavior has not yet been reported. 
The present work aims to examine the dynamic recrystallization characteristics during hot deformation, and the postdeformation recrystallization behavior (meta-dynamic and static recrystallization) of nuclear grade $316 \mathrm{LN}$ stainless steel, in order to establish the optimal hot-working conditions, i.e., the deformation temperature, strain rate, and strain and pass interval time.

1. Experimental Procedure. The material under study is $316 \mathrm{LN}$ steel with the chemical composition of $0.02 \mathrm{C}, 16.73 \mathrm{Cr}, 12.58 \mathrm{Ni}, 0.1 \mathrm{~N}, 2.58 \mathrm{Mo}, 1.63 \mathrm{Mn}, 0.61 \mathrm{Si}$ and bal. Fe. It was melted in an arc furnace followed by refinement and casting in vacuum. The compression test specimens with height of $15 \mathrm{~mm}$ and diameter of $8 \mathrm{~mm}$ were cut from the forged ingot. A Gleeble3500 thermal/mechanical simulator was employed for hot compression tests. The specimens were preheated at a rate of $10 \mathrm{~K} / \mathrm{s}$ to $1523 \mathrm{~K}\left(1250^{\circ} \mathrm{C}\right)$ (about $10 \mathrm{~min}$ ), which led to an initial grain size which was approximative $110 \mu \mathrm{m}$, and then cooled to the test temperature at a rate of $10 \mathrm{~K} / \mathrm{s}$, at which point the specimens were held for $5 \mathrm{~s}$ prior to deformation. Following this pretreatment, single-compression tests were carried out at temperatures between 1173 and $1473 \mathrm{~K}(1173,1273,1373$, and $1473 \mathrm{~K})$ at strain rates of $0.01,0.1,1$, and $10 \mathrm{~s}^{-1}$. After being deformed to a strain of 1.2 , the specimens were immediately quenched in water. Double-compression tests were performed at temperatures of $1173,1273,1373$, and $1473 \mathrm{~K}$ at a strain rate of $0.1 \mathrm{~s}^{-1}$, with the first loading performed at a strain of 0.3 . Following the first loading, the specimens were unloaded and held at their deformation temperature for $0.5-1200 \mathrm{~s}$, before a second loading to a strain of 0.6 was performed at the same strain rate. The microstructure was observed after the deformed specimens being cut parallel to the compressed direction followed by etching for 10-30 s with aqua regia.

\section{Results and Discussion.}

\subsection{Dynamic Recrystallization Characteristics.}

2.1.1. Flow Behavior of Single Compression. Figure 1 shows the single-compression flow curves of specimens deformed between $1173-1473 \mathrm{~K}$ and at strain rates of 0.1 and 10 $\mathrm{s}^{-1}$. It can be seen that, at the early stages of deformation, the peak stress, peak strain and work hardening rate all increase with increasing strain rate and decreasing temperature. At $0.1 \mathrm{~s}^{-1}$, the material exhibits softening after attaining a peak value and then reaches a plateau (Fig. 1a). However, at $10 \mathrm{~s}^{-1}$, softening is not apparent. The peak stress of the $316 \mathrm{LN}$ steel used in this study is comparable to that reported in [5]; both values are about $10 \%$ higher than that of 316 stainless steel [2]. It should be note that the flow behavior of $316 \mathrm{LN}$ steel can be influenced by DRX, deformation heat, cracking, and flow instability.

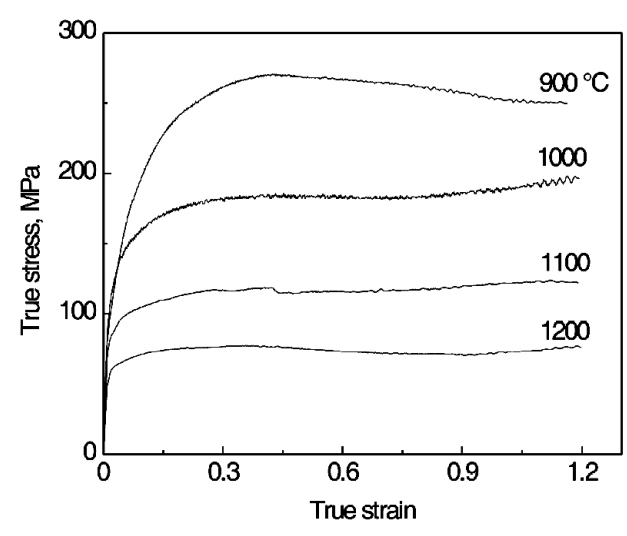

a

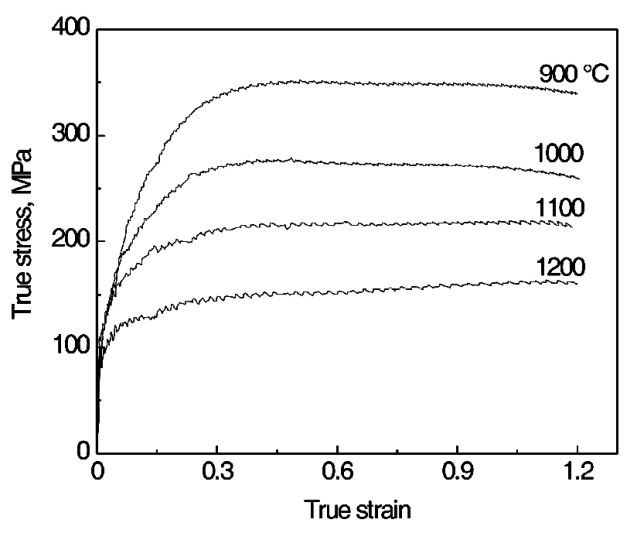

b

Fig. 1. Single-compression flow curves of $316 \mathrm{LN}$ stainless steel deformed at different strain rates: 0.1 (a) and $10 \mathrm{~s}^{-1}$ (b). 
2.1.2. Hot Deformation Equation and $Z$ Parameter. When the metal is deformed at elevated temperatures [6], the relationship between the experimental temperature, strain rate, and peak stress i.e., the hot deformation equation, can be described as follows:

$$
\dot{\varepsilon}=A[\sinh (\alpha \sigma)]^{n} \exp (-Q / R T),
$$

where $A$ and $\alpha$ are material constants, $n$ is the stress exponent, $\sigma$ is the peak stress, $Q$ is the hot deformation activation energy, $R$ is the gas constant, and $T$ is the absolute temperature. Using the linear regression method, as described elsewhere [7], each parameter can be obtained: $A=9.56 \cdot 10^{16}, \alpha=0.006, n=6.08$, and $Q=451 \mathrm{~kJ} / \mathrm{mol}$. The value of $Q$ is higher than that reported for 316 stainless steel (398 [2] and $413.8 \mathrm{~kJ} / \mathrm{mol}$ [4]). Thus, the addition of nitrogen increases the hot deformation activation energy, since increasing interstitial atoms may restrain the dislocation glide. The hot deformation equation and $Z$ parameter of $316 \mathrm{LN}$ stainless steel deformed at temperatures ranging from 1173 to $1473 \mathrm{~K}$ at strain rates between $0.01-10 \mathrm{~s}^{-1}$ can be expressed as follows:

$$
\begin{gathered}
\dot{\varepsilon}=9.56 \cdot 10^{16}[\sinh (0.006 \sigma)]^{6.08} \exp (-451000 / R T), \\
Z=\dot{\varepsilon} \exp (451000 / R T) .
\end{gathered}
$$

2.1.3. Critical Stress for DRX. Poliak [8] and Najafizadeh [9] verified that the initiation of DRX is effected by the inflection in the curve of the strain hardening rate $\theta$ vs. flow stress $\sigma$. The simplest equation with an inflection point, which fits the experimental $\theta-\sigma$ data from zero to the peak stress, is

$$
\theta=A \sigma^{3}+B \sigma^{2}+C \sigma+D
$$

where $\theta=d \sigma / d \varepsilon, A, B, C$, and $D$ are constants for a given set of deformation conditions. Derivation of Eq. (4) yields

$$
\frac{d \theta}{d \sigma}=3 A \sigma^{2}+2 B \sigma+C
$$

The minimum value of this second-order equation corresponds to the critical stress, i.e., $\sigma_{c}=-B / 3 A$. Based on the flow data of 316LN stainless steel in Fig. 1 and Eq. (5), the relationship between the critical stress for the $\ln (Z)$ and initiation of DRX can be obtained. Using a linear regression, the following quantitative relationship between $\sigma_{c}$ and $\ln (Z)$ can be obtained

$$
\sigma_{c}=15.9 \ln (Z)-495(\mathrm{MPa})
$$

\subsubsection{DRX Structure. Microstructure of $316 \mathrm{LN}$ stainless steel loaded to a strain of 1.2} at a strain rate of $0.01 \mathrm{~s}^{-1}$ between $1173-1473 \mathrm{~K}$ is shown in Fig. 2. At $1173 \mathrm{~K}$, small grains appear around elongated grains (Fig. 2a), which is referred to as a "necklace structure" or "necklace DRX" [10]. Both the recrystallization fractions and grain sizes of 316LN stainless steel deformed at $1273 \mathrm{~K}$ are higher than those deformed at $1173 \mathrm{~K}$. In addition, the characteristics of the necklace structure are not clear and the microstructure belongs to the conventional DRX type (Fig. 2b). When the deformation temperature is $1373 \mathrm{~K}$, the steel is completely recrystallized, the grain boundaries have a certain curvature, and numerous twins appear. At $1473 \mathrm{~K}\left(1200^{\circ} \mathrm{C}\right)$, full recrystallization also occurs, while the average grain size increases to $37 \mu \mathrm{m}$ (Fig. 2d). 

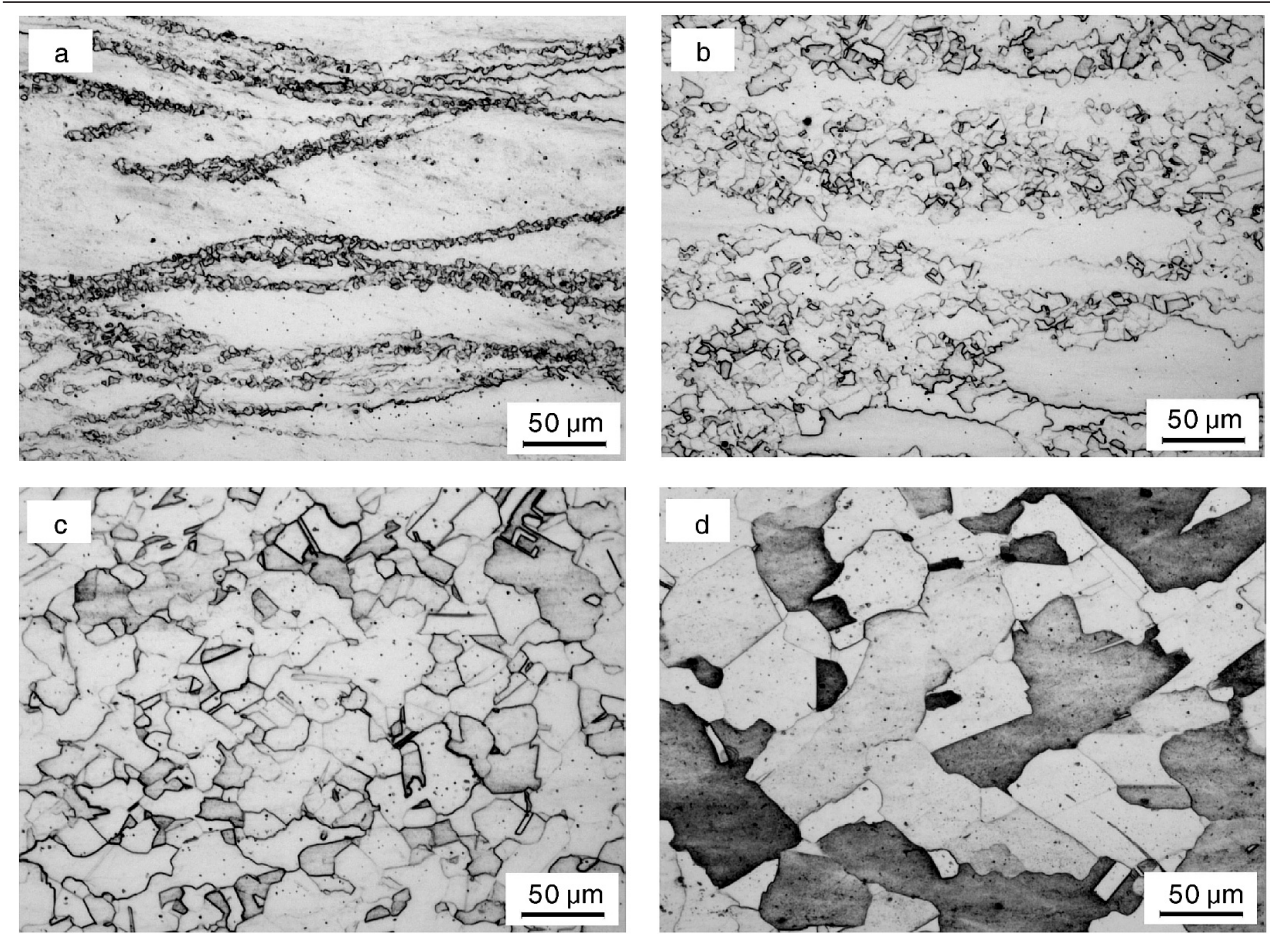

Fig. 2. Microstructures of $316 \mathrm{LN}$ stainless steel deformed at a rate of $0.01 \mathrm{~s}^{-1}$ to a strain of 1.2 at different temperatures: (a) $1173 \mathrm{~K}\left(900^{\circ} \mathrm{C}\right)$; (b) $1273 \mathrm{~K}\left(1000^{\circ} \mathrm{C}\right)$; (c) $1373 \mathrm{~K}\left(1100^{\circ} \mathrm{C}\right)$; (d) $1473 \mathrm{~K}$ $\left(1200^{\circ} \mathrm{C}\right)$.

Based on Fig. 2 and other microstructure observations, it can be concluded that DRX is developed by the conventional mechanism (DRX grains nucleate at triple junctions) at low $Z$ values and by the necklace mechanism at high $Z$ values. Here the critical $Z$ value is about $3.6 \cdot 10^{16}$, which is higher than that of 316 stainless steel [2]. By using the linear intercept method, the dependence of the DRX grain size on the deformation conditions can be obtained. The higher the $Z$ value, the finer the new grain. Under the same deformation conditions, the $D$ value of $316 \mathrm{LN}$ stainless steel is smaller than that of 316 stainless steel [2]. The relationship between $D$ and the parameters $Z$ and $A$ can be expressed as follows:

$$
D=2.32(Z / A)^{-0.22}(\mu \mathrm{m})
$$

\subsection{Postdeformation Recrystallization Behavior.}

2.2.1. Flow Behavior of Double Compression. The double-compression flow curves of 316LN stainless steel loaded at 1173 and $1373 \mathrm{~K}$ are shown in Fig. 3. It can be found that the longer the interpass time, the lower the yield stress of the second deformation, i.e., the softening fraction becomes larger. In addition, the softening rate becomes higher with deformation temperature. Sinse the first compression is close to the peak strain, the softening mechanisms include static and meta-dynamic recrystallization [11].

2.2.2. Postdeformation Softening Behavior. The softening fraction (i.e., the recrystallization factor) $X$ can be calculated by the data from the double-compression tests, as shown in Eq. (8) [12]:

$$
X=\frac{\sigma_{2}-\sigma_{3}}{\sigma_{2}-\sigma_{1}}
$$




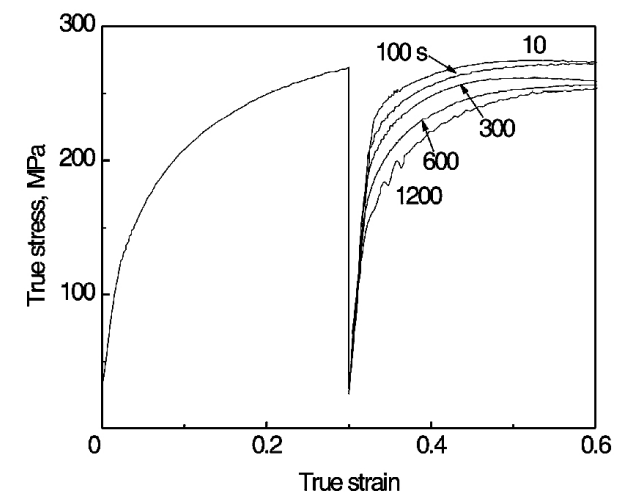

a

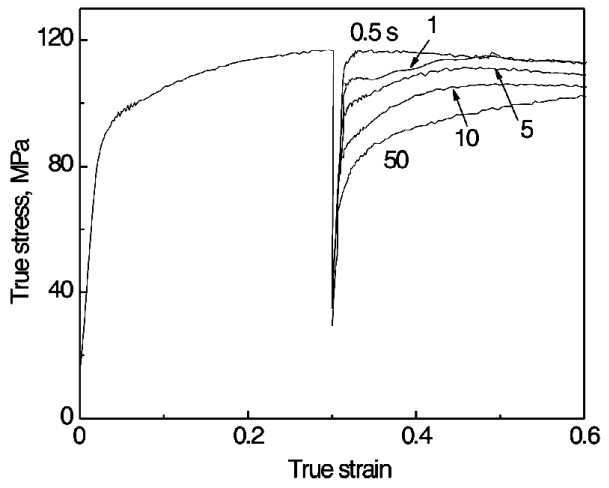

b

Fig. 3. Double-compression flow curves of $316 \mathrm{LN}$ stainless steel loaded at $1173 \mathrm{~K}\left(900^{\circ} \mathrm{C}\right)$ (a) and $1373 \mathrm{~K}\left(1100^{\circ} \mathrm{C}\right)(\mathrm{b})$.

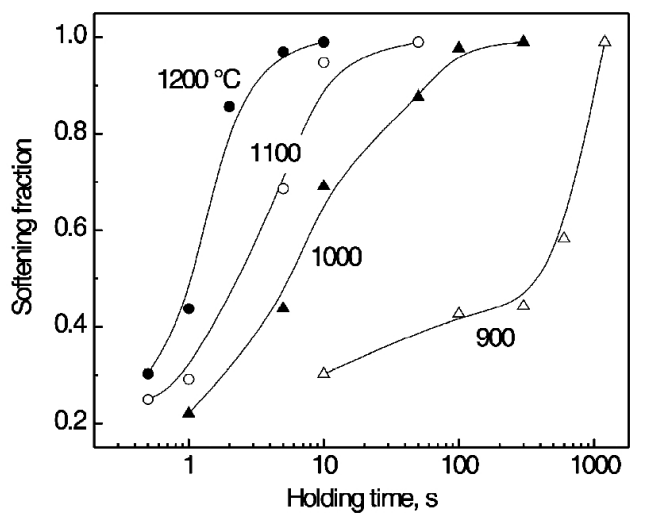

Fig. 4. Softening fraction as a function of holding time for $316 \mathrm{LN}$ stainless steel tested at different temperatures.

where $\sigma_{1}$ is the yield stress of the first loading, $\sigma_{2}$ is the flow stress at the end of the first loading, and $\sigma_{3}$ is the yield stress of the second loading. Figure 4 shows the softening fraction data as a function of holding time for the specimens loaded at different temperatures to a strain of 0.3 . It can be seen that the softening fraction curve is S-shaped above $1273 \mathrm{~K}$ $\left(1000^{\circ} \mathrm{C}\right)$. However, a plateau appears at $1173 \mathrm{~K}\left(900^{\circ} \mathrm{C}\right)$, which means that there is almost no softening for a certain period. This phenomenon can be attributed to $\mathrm{Cr}_{2} \mathrm{~N}$ precipitation [13], where the onset and offset of the plateau represent the beginning and termination of precipitation, respectively.

2.2.3. Postdeformation Recrystallization Characteristics. According to the S-shaped pattern of the softening fraction curves (Fig. 4), the Avrami-type equation for this behavior [11] could be expressed by the following formula:

$$
X=1-\exp \left[-0.693\left(t / t_{0.5}\right)^{n}\right]
$$

where $t$ is the interpass time, $t_{0.5}$ is the time corresponding to a softening fraction of 0.5 , and $n$ is the Avrami exponent, which can be determined from the gradient of a plot of $\ln (\ln [1 /(1-X)])$ against $\ln t$. It has been reported that the Avrami exponent in microalloyed steels can be affected by the deformation parameters [14, 15]. However, in austenitic 
stainless steels, it was found that the deformation parameters do not significantly affect the value of $n[11,16]$. In the present study, the results do not show any strong effect of temperature on the $n$ value, and the average value determined was 0.68 . Therefore, at the temperatures from 1273 to $1473 \mathrm{~K}$, the kinetic equation for postdeformation recrystallization of $316 \mathrm{LN}$ stainless steel is

$$
X=1-\exp \left[-0.693\left(t / t_{0.5}\right)^{0.68}\right] .
$$

The activation energy for postdeformation recrystallization can be obtained, as described in [17]. For 316LN steel tested between $1173-1473 \mathrm{~K}\left(900-1200^{\circ} \mathrm{C}\right)$ and at a strain rate of $0.1 \mathrm{~s}^{-1}, Q_{\text {rex }}$ is $129 \mathrm{~kJ} / \mathrm{mol}$, which is slightly lower than the static recrystallization $(137 \mathrm{~kJ} / \mathrm{mol})$ and meta-dynamic recrystallization $(155 \mathrm{~kJ} / \mathrm{mol})$ energies of 316 stainless steel deformed in the same temperature range [15].

Conclusions. Single- and double-compression tests were performed for nuclear-grade 316LN stainless steel, and its dynamic and post-crystallization deformation behavior was investigated. through analysis of the stress-strain curves and microstructure evolution. It was found that DRX occurred by the conventional mechanism at low $Z$ values and by the necklace mechanism at high $Z$ values. The quantitative relationship between $D$ and $Z$ was also determined. In the temperature range 1273-1473 K, the softening behavior of the steel after deformation is characterized by an Avrami-type equation.

Acknowledgments. The project is supported by the Natural Science Foundation Steel and Iron Foundation of Hebei Province (Grant No. E2013203110).

1. N. D. Ryan and H. J. McQueen, "Flow stress, dynamic restoration, strain hardening and ductility in hot-workingof 316 steel," J. Mater. Process. Technol., 21, Issue 2, 177-199 (1990).

2. M. Jafari and A. Najafizadeh, "Correlation between Zener-Hollomon parameter and necklace DRX during hot deformation of 316 stainless steel," Mater. Sci. Eng. A, 501, 16-25 (2009).

3. N. D. Ryan and H. J. McQueen, "Hot strength and microstructural evolution of 316 stainless steel during simulated multistage deformation by torsion," J. Mater. Process. Technol., 36, Issue 2, 103-123 (1993).

4. Sung-Il Kim, Youngseog Lee, and Byoung-Lok Jang, "Modeling of recrystallization and austenite grain size for AISI 316 stainless steel and its application to hot bar rolling," Mater. Sci. Eng. A, 357, 235-239 (2003).

5. Dipti Samantaray, Sumantra Mandal, C. Phaniraj, and A. K. Bhaduri, "Flow behavior and microstructural evolution during hot deformation of AISI type $316 \mathrm{~L}(\mathrm{~N})$ austenitic stainless steel," Mater. Sci. Eng. A, 528, 8565-8572 (2011).

6. C. M. Sellars, "Modelling - an interdisciplinary activity," in: S. Yue (Ed.), Proc. Int. Symp. on Mathematical Modelling of hot-rollingof Steel, Hamilton, ON, Canada (1990), pp. 1-18.

7. Y. H. Lu, R. D. Fu, and L. Qiu, "Deformation behavior of nitrogen strengthened high manganese austenitic steel," Trans. Mater. Heat Treat., 28, No. 2, 69-72 (2007).

8. E. I. Poliak and J. J. Jonas, "Initiation of dynamic recrystallization in constant strain rate hot deformation," ISIJ Int., 43, No. 5, 684-691 (2003).

9. A. Najafizadeh and J. J. Jonas, "Predicting the critical stress for initiation of dynamic recrystallization," ISIJ Int., 46, No. 11, 1679-1684 (2006).

10. D. Ponge and G. Gottstein, "Necklace formation during dynamic recrystallization: mechanisms and impact on flow behavior," Acta Mater., 46, No. 1, 69-80 (1998). 
11. A. Dehghan-Manshadi, M. R. Barnett, and P. D. Hodgson, "Hot deformation and recrystallization of austnitic stainless steel. Part 2: postdeformation recrystallization," Metall. Mater. Trans. A, 39, 1371-1381 (2008).

12. R. A. P. Djaic and J. J. Jonas, "Recrystallization of high carbon steel between intervals of high temperature deformation," Metall. Trans. A, 4, 621-624 (1973).

13. W. H. Zhang, Z. H. Wang, D. L. Zhao, et al., "Phase diagram calculation and micro-alloying design of nuclear grade 316LN steel," J. Yanshan Univ., 35, No. 6, 519-522 (2011).

14. S. F. Medina and J. E. Mancilla, "Determination of static recrystallization critical temperature of austenite in microalloyed steels," ISIJ Int., 33, No. 12, 1257-1264 (1993).

15. L. P. Karjalainen, T. M. Maccagno, and J. J. Jonas, "Softening and flow stress behavior of $\mathrm{Nb}$ microalloyed steels during hot-rollingsimulation," ISIJ Int., 35, No. 12, 1523-1531 (1995).

16. A. S. Taylor and P. D. Hodgson, "The postdeformation recrystallization behavior of 304 stainless steel following high strain rate deformation," Mater. Sci. Eng. A, 529, 164-169 (2011). 